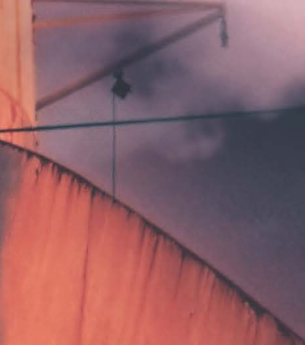

African perspectives on selected marine, maritime and

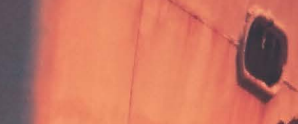

)
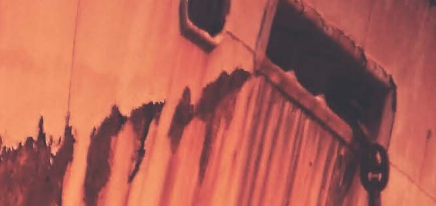

:

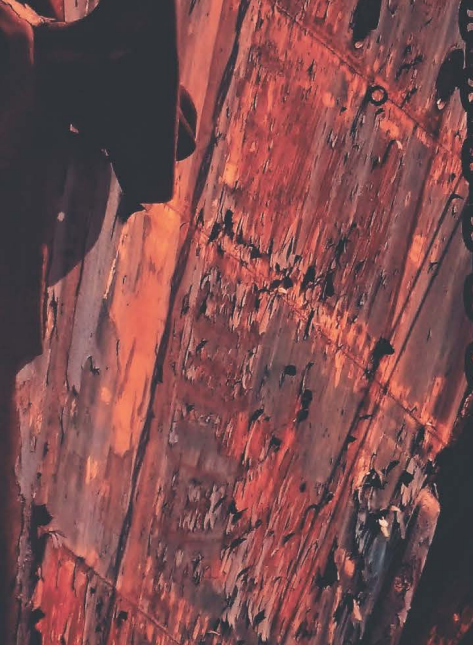

Patrick Vrancken \& Char! Hugo (Eds)

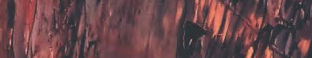

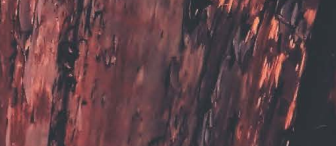
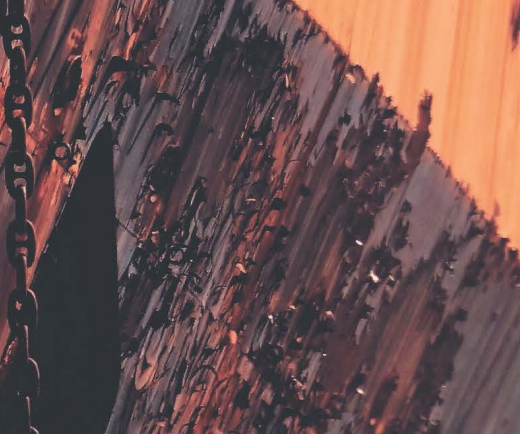
international trade law topics 


\section{ASPECTS OF THE BILL OF LADING AS A DOCUMENT OF TITLE IN THE ERAS OF THE THIRD AND FOURTH INDUSTRIAL REVOLUTIONS}

SAREL F DU TOIT ${ }^{\star}$

* Professor, Department of Mercantile Law, University of Johannesburg. 


\title{
INTRODUCTION
}

South African mercantile law, with its roots in the lex mercatoria and forming part of a partially uncodified mixed jurisdiction, has always been inherently flexible and adaptable to new circumstances. ${ }^{1}$ Usually, the law has to adapt to new technology and would be able to do so without legislative intervention, but the story of the electronic bill of lading is a rare case where the law had been kept waiting by technology. In 2001, the author concluded:

\begin{abstract}
"It seems that the only way in which a bill of lading can be replicated is by way of a registry. There is no unique electronic document that can live a life of its own.... The fact that uniqueness in a digital world is achieved by way of a registry is not due to any legal shortcoming, but today at least is a characteristic of the available technology". ${ }^{2}$
\end{abstract}

Thus, a truly free electronic bill of lading, as easy to issue and use as a paper bill of lading, without the participants having to form part of a closed registry, was not possible in the not too distant past. In the years since the correct - though perhaps unfortunate - statement quoted above, Bitcoin emerged from the shadows and, more importantly, led to the widespread acceptance of blockchain technology.

This chapter will provide a recent historical overview of attempts to dematerialise the bill of lading during the Third Industrial Revolution - "the shift from mechanical and analogue electronic technology to digital electronics"3 from the 1970s to the 1990s. But an electronic bill of lading could only advance so far during the computer age. For electronic bills of lading, technology has at last caught up and, in the Fourth Industrial Revolution, ${ }^{4}$ the age of artificial intelligence

1 For but one example see London and South African Bank v Donald Currie \& Co (1875) 5 Buch 29 34: "The enormous development of commerce in recent times [the case was reported in 1875] requires a corresponding development of the mercantile law so that it becomes impossible to rigidly apply the rules which obtained in Holland in the beginning of the present century [the nineteenth century] to questions which arise out of customs of later growth". The Constitution of the Republic of South Africa, 1996 further determines that a court must, if necessary, develop the common law in order to give effect to a right in the Bill of Rights (s 8(3)(a)) and the Constitutional Court, the Supreme Court of Appeal and the High Court each has the inherent power to develop the common law, taking into account the interests of justice (s 173).

2 Du Toit "Towards electronic bills of lading: a South African perspective" in Weerasooria (ed) Financial Regulation and Payment Systems (2001) 121 153. A heading in an article by Herd (“"Blocks of lading' Distributed ledger technology and the disruption of sea carriage regulation" (2018) 18 QUT Law Review 306 308) states aptly: "The Internet: Not Quite the Technology to Dematerialise the Bill of Lading".

3 “Digital revolution” https://en.wikipedia.org/wiki/Digital_Revolution\#1970s (11-05-2019). The terms Third and Fourth Industrial Revolution are not used consistently by any stretch of the imagination.

4 “Industry 4.0” https://en.wikipedia.org/wiki/Industry_4.0 (11-05-2019). 
and so much more, blockchain made a negotiable electronic bill of lading possible. Blockchain is inevitably mentioned as one of the disruptive technologies of the Fourth Industrial Revolution (Industry 4.0), being inextricably linked with, and anchoring, the current Revolution. ${ }^{5}$ The chapter will further consider whether the law recognises such a blockchain bill of lading and, if it does, will consider whether the bill can effect delivery of the goods in terms of South African law. As such, the focus will be specifically on aspects of the bill of lading as a document of title. ${ }^{6}$ The characteristics of a bill of lading as a document of title in South African law are: a document of title is transferable; the holder of the document is (usually) in possession of the goods; the transfer of the document will (usually) transfer possession of the goods; the transfer of the document can (but will not necessarily) lead to a transfer of the ownership in the goods; and the holder of the document (usually) has a right to delivery of the goods against the carrier. ${ }^{7}$ The focus will be on whether these functions can be replicated by recognising an electronic bill of lading as a bill of lading, and whether the property-law consequences in respect of the underlying goods will remain undisturbed.

Throughout this chapter, the assumption will be that South African law applies to both the bill of lading and to any consequences in terms of the law of property in respect of the transported goods. ${ }^{8}$

5 A rudimentary Internet search will unearth titles such as "The Fourth Industrial Revolution built on blockchain and advanced with AI” (Pollock https://www.forbes.com/sites/darrynpollock/2018/11/30/the-fourth-industrialrevolution-built-on-blockchain-and-advanced-with-ai/\#6917401b4242 (11-05-2019)); the author will abstain from further references. AI will likely play an important role in the use of blockchain bills of lading, eg in the detection of fraud and money laundering, and "Internet of Things technology could provide real-time information about the location, temperature and condition of the goods and update the blockchain with this information" - Herd (n 2) 309, 310. For a clear explanation of blockchain technology, using an example from the island Yap, see Spruyt "An assessment of the emergent functions of virtual currencies" 2018 TSAR 707 709-710.

6 Contractual rights and obligations fall outside the scope of this chapter: see Du Toit The Bill of Lading in South African Law (2000 thesis RAU) ch 6.

7 For the reason of these qualifications and a more comprehensive explanation of the characteristics, see Du Toit (n 6) 129-131, and for an explanation of how the holder of the bill of lading can be said to be in possession of the goods, see 103-104. For the functions of a bill of lading, see Du Toit ch 5 and for the practical problems created by using a paper bill of lading, see ch 8 .

8 According to s 2(1)(a)-(b) of the Sea Transport Documents Act 65 of 2000, the Act applies "to any sea transport documents [including a bill of lading - s $1 s v$ "sea transport document" (a)-(c)] issued in the Republic" and - rather strangely - "to goods consigned to a destination in the Republic, or ... landed, delivered or discharged in the Republic". For criticism, see Du Toit “Comments on the Sea Transport Documents Act 65 of 2000" 2003 TSAR 731 732. The Act does not deal at all with many legal aspects regarding either the bills of lading or the goods in question. As far as these matters are concerned, the assumption is that South African law will apply (see s 6(1) of the Admiralty Jurisdiction Regulation Act 105 of 1993, in respect of what the South African law to be applied will look like, and Du Toit (n 6) ch 3, for an analysis). Regarding res in transitu and the law governing the validity of a transfer 


\section{THIRD INDUSTRIAL REVOLUTION}

\section{Before the registries ${ }^{9}$}

The only workable solution to replicating negotiable electronic bills of lading were registries such as SeaDocs ${ }^{10}$ and Bolero, ${ }^{11}$ among others. This was the only way in which the unique characteristics of a bill of lading could be preserved. These registries will not be discussed here. However, preceding the registries some innovative solutions, given the available technology, emerged which provided a roadmap towards the eventual adoption of blockchain bills of lading. These solutions also provided a legal framework enabling such bills of lading and identified some of the legal intricacies that may still hinder any future evolution of electronic bills of lading.

\section{Grönfors' Cargo Key Receipt ${ }^{12}$}

The Cargo Key Receipt (CKR) developed by Grönfors can be seen as a precursor to the negotiable electronic bills of lading. It was based on the Datafreight Receipt System (DRS) of the Atlantic Container Line (ACL), which has been in operation since 1971. The DRS was introduced because of the congestion caused by the late arrival of bills of lading. The system was built around the concept of the waybill and not the bill of lading. When writing in 1982, Grönfors felt that customers were not prepared to accept more sophisticated methods that, unlike in the case of a waybill, make provision for the negotiation of the transport document as does the bill of lading. ${ }^{13}$ Therefore, there is no negotiability or transferability. Nevertheless, the method is instructive because it illustrates how a paper document such as a waybill

of ownership, see Neels "Die lex causae vir eiendomsoordrag van res in transitu" 1991 TSAR 309. Cf UNCITRAL Model Law on Electronic Transferable Records (2017) art 1 and 19.

9 See Ong "Blockchain bills of lading” NUS Centre for Maritime Law Working Paper 18/07 Aug 2018 https://law. nus.edu.sg/cml/pdfs/wps/CML-WPS-1807.pdf (12-05-2019) 4-6.

10 See Bury “Electronic bills of lading: a never-ending story?” 2016 Tulane Maritime Law Journal 197 213-214; Du Toit (n 6) 272-276.

11 See Bury (n 10) 218-224 and 224 et seq for more recent developments; Du Toit (n 6) 309-317.

12 For an account of the history of the project, see Henriksen The Legal Aspect of Paper-less International Trade and Transport (1982) 97-99. The descriptions of the systems in par 2.2-2.5 are based on Du Toit (n 6) 254-261, 268-272, $278-281$.

13 Grönfors Cargo Key Receipt and Transport Document Replacement (1982) 43. 
can be replaced.The DRS operates in the following way. The necessary information is entered into a computer at the port of shipment, the shipper gets a receipt for the cargo and the information is transmitted to the port of destination. Before the ship arrives at its destination, the computer issues a notice of arrival informing the receiver of the date and time when she can collect her goods, and containing the other information originally entered into the computer. The notice is then mailed to the receiver. ${ }^{14}$ Although this system was a huge step forward, it did not make provision for parties other than the shipper, carrier and receiver to be involved, thus excluding a bank financing the transaction and demanding security. ${ }^{15}$ To remedy this shortcoming, Grönfors proposed Project NODISP. This system requires some further explanation before returning to the role of a bank.

While the shipper is in possession of the duplicate waybill (first copy of the waybill), she can change her instructions to the carrier by, for example, changing the port of destination. ${ }^{16}$ After handing this duplicate waybill over to the consignee or to a bank, the shipper cannot intervene anymore. To regulate this situation in a paperless environment, Grönfors proposed Project NODISP. The shipper makes the following declaration: "The shipper has irrevocably declared that he has assigned his right to control the goods during transport to the receiver of the goods" ${ }^{17}$ This declaration is entered into the computer, shown on the receipt given to the shipper and also reproduced in the documentation at the port of destination. Rather than using the full declaration, the declaration is shortened to the word "nodisp" that is reproduced on all relevant documentation. ${ }^{18}$ There is no need for the shipper to physically transfer a duplicate waybill to the consignee, nor is there a need for the consignee to be in possession of a duplicate waybill to

14 Grönfors (n 13) 15-16, 35.

15 A consignee also does not know that the shipper will not "resell or reroute the goods in transit" (see Kozolchyk "Evolution and present state of the ocean bill of lading from a banking law perspectice" 1992 Journal of Maritime Law and Commerce 161 220; Kozolchyk "The paperless letter of credit and related documents of title" 1992 Law and Contemporary Problems 39 86).

16 See Grönfors Towards Sea Waybills and Electronic Documents (1991) 27-28. Regarding the duplicate waybill, Grönfors states that it is "only used as an easy way to prove who has the right to control but not as a necessary condition for having such right" (51). A further advancement is that a duplicate sea waybill is seldom issued, and thus an express declaration similar to "nodisp" discussed below is used to facilitate transfer of the right of control to the consignee. The idea was taken from the Cargo Key Receipt pattern (55-56). Cf rule 6 of the CMI Uniform Rules for Sea Waybills (dealing with the right of control).

17 Also see Grönfors (n 13) 77-79.

18 Grönfors (n 13) 27-28. 
ensure nobody interferes with the delivery of the goods. ${ }^{19}$ The only unavoidable printout is the receipt given to the shipper in exchange for the goods so that he can check whether the information is correct. ${ }^{20}$

Holding a waybill does not give the holder any right to delivery of the goods because the goods are simply delivered to the receiver indicated on the waybill - the waybill is not presented in exchange of the goods. Therefore, even though a financing bank is in possession of the waybill, it is usually indicated as the receiver on the waybill as well, and the real receiver of the goods is indicated by way of a notify address only: "By this legal 'trick' the non-negotiable character of the document is, so to speak circumvented and the bank's grip on the goods when they have arrived at the place of final destination remains firm". ${ }^{21}$ Under the computerised system, a bank will be satisfied when it sees the receipt with a "nodisp" clause indicating that it is the receiver of the goods. ${ }^{22}$ The bank now knows that nobody can interfere with the delivery of the goods to it (if necessary). It is in the same position as being in possession of the duplicate (paper) waybill indicating that it is the receiver of the goods. A bank will further not accept a claused waybill (for example showing that the goods are defective in some way) as security. For that reason, the code word "clean" must be added together with "nodisp" in order to satisfy a bank. ${ }^{23}$

The CKR system as adopted by ACL works in the following way when used in conjunction with a letter of credit. ${ }^{24} \mathrm{~A}$ letter of credit is opened in favour of the seller, payable against presentation of a CKR. After the shipment of the goods, the shipper (seller) gets the first printout of the CKR, which is marked "nodisp", "clean"

19 According to Grönfors (n 13) 36, "the basic idea was to 'translate' the function of the duplicate waybill by the express NODISP declaration by the carrier, thus using the computer as bearer of the same function".

20 Grönfors (n 13) 33, 37-38.

21 Grönfors (n 13) 27, 43-44.

22 Grönfors (n 13) 31-32. See also at 38 where the author wrote: "The delivery of this receipt to the bank means, that the bank can rely upon the fact that these data were in fact stored into the record of the carrier's computer and that their correctness at that very moment was checked by the carrier against the real goods taken in charge". (Italics omitted.)

23 Grönfors (n 13) 39, 77-79. See also at 86-87, where the author points out that a further code word, "security", was later added because of objections by banks wanting more security. The code word means that the carrier undertakes to hold the goods as specified in the receipt as security and collateral for the bank named as consignee. See further Grönfors (n 16) 76.

24 For a full description, see Grönfors (n 13) 96-98, 101, 36-37. 
and "security" and indicates the name of the buyer's bank (who opened the letter of credit) as consignee. The information is transmitted to the port of destination. The seller is paid by her bank against surrender of the CKR. The seller's bank transmits the necessary information to the buyer's bank, informing it that it has debited the account of the buyer's bank. The latter in turn debits the buyer's account. Before the ship's arrival, the buyer's bank gets the notice of arrival, which includes a CKR attached to it and states that "the goods will be delivered against the enclosed Cargo Key Receipt duly assigned by the bank as consignee". The buyer is also notified as the notify addressee. When the buyer's bank obtains payment from the buyer, it assigns the CKR to the buyer, who then demands delivery of the goods from the carrier.

The system can be further refined by issuing the receipt to the shipper and the notice of arrival at the port of destination electronically, and transmitting the information to the bank electronically, but this will not change the basic functions of the system. ${ }^{25}$

The system ${ }^{26}$ "has been successfully tried out in full scale [in the 1980s] but is not yet regularly used". ${ }^{27}$ The main disadvantage is that the system is an initiative of one carrier and is therefore limited to the ports that the carrier visits. ${ }^{28}$ Traders who are not regular customers of the carrier might view the system with suspicion and financing banks (especially the exporter's bank) might not be interested in the system..$^{29}$ An odd feature of the system, when a bank is involved, is the delivery of the goods against presentation of the CKR, usually assigned (that is indorsed) by the bank to the buyer. As Toh See Kiat ${ }^{30}$ wrote, "[p]erhaps this physicality was

25 Grönfors (n 13) 40.

26 See Grönfors (n 13) 80-95 for objections raised by Swedish and American banks to the system, and his response to those objections.

27 Grönfors (n 16) 76; Grönfors (n 13) 95, 96. It seems that the system was "mothballed”: see Kozolchyk "Evolution" (n 15) 222-223.

28 Toh See Kiat Paperless International Trade: Law of Telematic Data Interchange (1992) 184; Urbach "The electronic presentation and transfer of shipping documents" in Goode (ed) Electronic Banking:The Legal Implications (1985) 115.

29 Toh See Kiat (n 28) 217 n 168 wrote that the exporter's financier "has no means of protecting himself should his principal (the importer's financier) fail to reimburse the payment or become insolvent. All he has is a worthless CKR - he cannot sell it, he cannot claim the goods on it, he cannot eat it. This is perhaps another reason for the unpopularity of the CKR idea - the financiers likely to be involved are financiers with such close, established relationships that there cannot be many of them in world-wide context". See Kiat 185, 216-217 n 166, who correctly rejected the argument of Grönfors (n 13) 58, 91 that the consignor (seller) can resume the right of disposal if the buyer, for example, refuses to pay or to receive the goods.

30 (n 28) 184. Also see Goode Proprietary Rights and Insolvency in Sales Transactions (1989) 81. 
permitted to raise the enthusiasm of the financiers in the project". This does not really cause a problem because the CKR is not posted at the port of shipment to the port of discharge, and both the buyer and the buyer's bank are physically situated at, or near, the port of discharge. There is nevertheless no need to deliver against a CKR: the carrier knows that the bank is the consignee and it will deliver the goods to the bank unless the bank instructs the carrier otherwise in whatever way. There is no need for the carrier to see the CKR.

Toh See Kiat ${ }^{31}$ wrote that the CKR system "is nothing more than a sea waybill with a 'NODISP' handicap" and it can therefore not be attractive to an exporter. It is nevertheless submitted that this system was a sound way to replace the waybill at the time. The electronic transmission of information is an improvement over a paper waybill. The limitation of this system - and this is not a criticism as the system was never designed to replace the bill of lading - is that the goods cannot be traded en route. ${ }^{32}$

\section{Reinskou's Notification-Confirmation System}

The system proposed by Reinskou seems clear and simple at first glance. This may largely be because of the fact that it contains none of the details of the CMI Rules for Electronic Bills of Lading or the even more comprehensive rules of functioning registries. Reinskou followed a functional approach, leaving him free from the shackles of the traditional bill of lading: "the problem is not how to construct a system to which the law on negotiability is applicable. The problem is how to make a system that will lead to the same legal consequences

31 (n 28) 185.

32 See, however, Grönfors (n 13) 67 and the criticism of Toh See Kiat (n 28) 184-185. Grönfors (n 16) 59-60 proposed that the waybill pattern can be elaborated to get closer to the bill of lading pattern, by allowing the consignee to assign his right to control and right to obtain delivery to another party (apart from the bank assigning its right to claim delivery to the real buyer). The consignee must also expressly notify the carrier of the assignment. It is submitted, however, that, if a bill of lading is needed, a bill of lading or an electronic equivalent of the bill of lading should be used. The bill of lading developed precisely because of the uncertainty and chaos that might develop in a long chain of assignments without embodying the right that is assigned in a paper document, which also tells the carrier to whom delivery must be made. Toh See Kiat 185 indicated why such an assignment is not possible in English law. Even if it were, it should be avoided. 
as those which today follow from the law on negotiability". 33 The system works in the following way: ${ }^{34}$

"The fundamental idea is the conception of a notification-confirmation system. Whenever a right in the goods is created or assigned, the transferor notifies the carrier of the transaction. The carrier registers the change and sends the transferee [the "lawful receiver"] a confirmation of his acquired right. If e.g. the goods are sold while at sea, the seller who is registered as the owner, will notify the carrier of the sale. The carrier registers the buyer as the new owner and confirms to him that he is now the owner of the goods".

The first confirmation is issued by the carrier ${ }^{35}$ to the shipper after the shipment of the goods, unless the carrier is already notified of a sale of the goods, in which case the confirmation will be sent to the buyer and a "duplicate" to the shipper as a receipt. ${ }^{36}$ The confirmation sent by the carrier will include the contract of carriage as well as a description of the goods as in a regular bill of lading. ${ }^{37}$ Reinskou stressed that "the legally significant events for the creation of legal rights and obligations are the messages themselves. The carrier's registration of the notifications and the information stored in his computer are of no legal consequence in this process". ${ }^{38}$ The electronic process is used for speed and efficiency in the delivery of the messages. Negotiability and other essential characteristics of the traditional bill of lading are created by contractual means. The original contract of carriage will state that the carrier will issue confirmations to transferees after being notified by a transferor and every confirmation will contain the same clause binding the carrier to take part in the system. According to Reinskou, the confirmation "is formulated as an independent [unilateral]

33 Reinskou "Bills of lading and ADP: description of a computerized system for carriage of goods by sea" 1981 Journal of Media Law and Practice 161. Reinskou wrote at 160 that " $[\mathrm{t}]$ he conclusion to draw [...] is that there is no serious legal or technical obstacle to computerization, or to put it into Latin: Navigare necesse est, Documenta non sunt necessaria".

34 Reinskou (n 33) 162.

35 There is, of course, no need for the computer equipment to be physically located on the ship. See Reinskou (n 33) 179 .

36 Reinskou (n 33) 172-173. The original information (such as a description of the goods) may be transmitted directly from the shipper to the carrier. The carrier then checks the information and adds to it, if necessary, before issuing the confirmation.

37 Reinskou (n 33) 162.

38 Reinskou (n 33) 163. 
promise" that "will govern the contractual relationship between the carrier and the buyer" ${ }^{39}$ The promise irrevocably binds the promisor. In South African terms, it would perhaps be clearer to state that an offer is made by the carrier to carry the goods on the terms set out in the confirmation, which is of course the same as the original contract of carriage. ${ }^{40}$ The contract of carriage and confirmations will further stipulate that the carrier is discharged if it delivers the goods in good faith to the party to whom it transmitted the last confirmation (normally the carrier is discharged when delivering to the holder of a bill of lading without any notice or knowledge of irregularities). ${ }^{41}$ When a letter of credit is used, the seller notifies the carrier of a transfer to the nominated bank and the carrier confirms to the nominated bank. The latter pays the seller if there are no irregularities. The nominated bank in turn notifies the carrier of a transfer to the issuing bank and the carrier confirms to the issuing bank. The transfer from the issuing bank to the buyer will take place in the same way, usually when the buyer pays the bank. ${ }^{42}$ Security will be achieved by way of public-key cryptography. ${ }^{43}$

The most obvious deterrent of the system is that it imposes a burden on the carrier that it did not have to bear previously. ${ }^{44}$ This is admitted by Reinskou ${ }^{45}$ but, of course, the carrier will recoup its expenses by way of higher freight. ${ }^{46}$ The further problem with such a system is that it will be available only to participants. Reinskou ${ }^{47}$ indicated that, when goods are sold to an outsider, the carrier can issue a normal bill of lading after the notification and at the request of the seller. Further negotiation within the system is then suspended. In the extract on how the system works that was quoted above, Reinskou indicated that a party will be registered as the owner of the goods. This approach should not be followed. Instead, a party

\footnotetext{
39 Reinskou (n 33) 166.

40 Reinskou wrote against the background of Scandinavian law.

41 Reinskou (n 33) 167. See also at 170 for a summary of other contractual clauses.

42 Reinskou (n 33) 177-178, 184-185.

43 See Reinskou (n 33) 179-182.

44 See Basedow "Dokumentelose Wertbewegungen im Gütertransport” in Kreuzer (ed) Abschied vom Wertpapier? Dokumentelose Wertbewegungen Effekten-, Gütertransport- und Zahlungsverkehr (1988) 96-97.

45 (n 33) 186.

46 Traders might not be so willing to pay for the additional costs of communications. See Toh See Kiat (n 28$) 186$.

47 (n 33) 185.
} 
should be registered as the holder of the bill of lading and questions of ownership should be left to the law that governs the transaction. There is no definite link between being the holder of a bill of lading and being the owner of the goods. Another difficulty is getting all the parties to agree on the very detailed contract that is required. ${ }^{48}$ It should also not be forgotten that the system is of course essentially a registry kept by the carrier.

Toh See Kiat ${ }^{49}$ wrote that Reinskou's system appears at first glance to be very similar to the CMI Rules on Electronic Bills of Lading. Toh See Kiat nevertheless stated that the fundamental difference between the systems is that "Reinskou aims to reproduce the effects of the bill of lading by means of a contractual arrangement (a legal technique) [while the CMI Rules] uses a technical technique (supported by a contract) to do the same". It is not clear why this should make any difference, and whether there even is such a fundamental difference between the two systems to warrant the one being classified as a functional approach and the other as a technical approach. It is submitted that both these systems are based on the functional approach. A multitude of aspects has not been considered in Reinskou's system, compared to, for example, the CMI Rules on Electronic Bills of Lading. This is not so much a criticism of Reinskou's theoretical system as an indication that, in practice, the statutory or contractual framework will need to be extremely comprehensive.

\section{Henriksen's Special Technical Method}

Henriksen devised a special technical method to provide for negotiability. The system was developed in response to Grönfors' CKR and Reinskou's

48 Toh See Kiat (n 28) 186. The liability of the carrier in the case of miscommunication or system failure should be extensively governed in the contract. Toh See Kiat also indicated that there are privity-of-contract issues and problems regarding consideration in English law if the carrier does not send a confirmation to a transferee, because the latter is then not a party to the contract. The contract of carriage between the shipper and the carrier, in which the carrier undertakes to send confirmations to subsequent transferees, can be regarded as a stipulatio alteri in South African terms. A delictual claim might also provide some degree of relief to such a transferee. The problem of consideration does not arise in South African law. On the other hand, Toh See Kiat indicated that, while the carrier might be exonerated by the contract of carriage against wrongful delivery, the carrier is still not protected from a suit in tort instituted by a non-participant. In South African terms, it will at least be necessary to prove that the carrier was negligent before a delictual claim will succeed and, as in the case of the traditional bill of lading, the carrier is unlikely to be negligent when he delivered to the last confirmed transferee without notice of any irregularities.

49 (n 28) 186. 
Notification-Confirmation System. As Henriksen emphatically stated, he was not criticising the juristic work of Grönfors or Reinskou, but rather the functional approach adopted for these two projects whereby the technique of possession and surrender of a physical paper document is replaced by another technique with the same legal consequences. ${ }^{50}$ Henriksen preferred a technical approach because then a completely new legal technique does not need to be developed and a new technique with many different legal consequences in different countries is avoided. ${ }^{51}$ Probably the most important consideration for Henriksen is that a technical approach will not lead to widespread legal uncertainty. The rules relating to the traditional paper system were clarified over a long period through use and interpretation by the courts and, therefore, parties bound by these rules do not generally run into unforeseen complications. The clear rules relating to the existing paper system can be applied to a large extent when researching a technical approach. ${ }^{52}$ Taking the technical approach as a starting point, Henriksen described his approach in the following way: ${ }^{53}$

"A document consists of a piece of paper (or something similar) to which various forms of data are committed. We wish to eliminate the paper, not the necessary data. Today legal consequences attach to possession and surrender of the actual paper document. The first thing that suggests itself is to attach these legal effects to what remains after the paper is eliminated - i.e. the data. Thus the idea is that the present-day document shall be replaced by 'original data contents' - something tangible - and that possession and surrender of these original data contents, such as the data contents of a $\mathrm{B} / \mathrm{L}$, shall be endowed with exactly the same legal effects in all respects as possession and surrender of the original paper document (e.g. B/L) has today. ... In the event this idea is realized, the symbolic function of the document will be linked with possession of the original data contents, not with the original document as in today's system".

The wording of a document indicates whether it is a bill of exchange, promissory note or bill of lading. Similarly, the particular formulation of the data contents will identify the type of document.

50 Henriksen (n 12) 119.

51 This stems from the fact that even the legal consequences of traditional paper routines differ from country to country. See Henriksen (n 12) 120.

52 Henriksen (n 12) 120.

53 Henriksen (n 12) 121. 
When dealing with concepts such as originality and uniqueness, which are essential for a paper document such as a bill of exchange, the drawback of publickey cryptography is that the transferor of a message can transmit the same message to different parties, as he always retains a copy of the message. ${ }^{54}$ Henriksen wrote that " $[t]$ he recipient will therefore be in the same position as if the data sender holds an unlimited (indefinite) number of original documents and transmits one of them to the recipient". ${ }^{55}$ Effross $^{56}$ concluded that, "[a]lthough PKI [public key infrastructure] would practically resolve many issues associated with negotiability, until the threat of cloned 'couriers without luggage' can be technologically eliminated the electronic negotiable instrument may well remain only a digital dream". Henriksen attempted to provide a solution to circumvent this problem.

The system makes use of public-key cryptography (the double encryption system) to confirm the identity of the sender of the message and ensure that only the transferee can read the message. As a point of departure, the computers used in the system are programmed to have three specific characteristics. ${ }^{57}$ First, the computer of the transferor erases the message when receipt of the message is confirmed by the transferee. Secondly, when X uses his secret key to encrypt a message entered into the computer by himself (that is not a message received from another party), the computer will add the phrase "generated by X" to the message. Of course, the computer must be programmed in such a way that $\mathrm{X}$ cannot prevent this from happening. The original message plus the additional phrase will then be encrypted to provide the digital signature of $\mathrm{X}$. Thirdly, if $\mathrm{X}$ adds to a message that he received from another party (that is not a message entered by himself) the computer adds the phrase "added by X" when X uses his secret key to encrypt the message. The message will then contain the original message that $\mathrm{X}$ received, the phrase added by

54 Apart from the fact that there will not be a single original, public-key cryptography can be used to transfer a message between more than two parties successively, adding additional information such as an indorsement where necessary. See Henriksen (n 12) 63-64; Effross "Notes on PKI and digital negotiability: would the cybercourier carry luggage?” (1998) 38 Jurimetrics: The Journal of Law, Science and Technology 385 390-391 for a description. According to Henriksen, he was the first person to describe this use of public-key cryptography whereby the transferee further transfers the message to a third party. The system is similar to the one described here, but without the three special characteristics of the computer (see below).

55 Henriksen (n 12) 122. Also see Perritt "Contract, evidence and agency issues" in Baum and Perritt Electronic Contracting, Publishing and EDI Law (1991) 365-366.

56 (n 54) 395.

57 Henriksen (n 12) 123-124. 
the computer and the additional information (such as an indorsement) added by X. All of this will be encrypted to provide the digital signature of X.

The system then works in the following way. ${ }^{58} \mathrm{~A}$ sends a message to $\mathrm{B}$ (message A). ${ }^{59}$ Message A contains "generated by A" (inserted by the computer just before encryption took place when $A$ signed the message using his secret key) and the original message. B "indorses" the message to C (message B). Message B contains "generated by A", the original message of A, "added by B" (inserted by the computer just before encryption took place when $\mathrm{B}$ signed the message using his secret key) and B's indorsement. When C is satisfied, C acknowledges receipt of the message to B and B's computer automatically erases the messages and signatures stored on it. ${ }^{60} \mathrm{~B}$ sent the digital signature of $\mathrm{A}$ and the digital signature of $\mathrm{B}$ to $\mathrm{C}$. $\mathrm{C}$ therefore has the digital signature of A, message A (arrived at by using the public key of $A$ on the digital signature of $A$ ), the digital signature of $B$ and message $B$ (arrived at by using the public key of $\mathrm{B}$ on the digital signature of $\mathrm{B}$ ). ${ }^{61}$

By comparing message $\mathrm{A}$ and message $\mathrm{B}, \mathrm{C}$ can see that they were generated by $A$ and an indorsement was added by B. Suppose that B wanted to commit fraud. $\mathrm{B}$ made a printout of A's digital signature before the message on his computer was erased by $\mathrm{C}$ confirming receipt of the message. $\mathrm{B}$ enters the digital signature from the printout into his computer and arrives at message A by using A's public key. B also adds an indorsement to D. When $\mathrm{B}$ signs the message, the phrase added will be "generated by B" because this message was not received from another party. The phrase "added by B" will not be included in the message because B did not add anything to a message that he received from another party. When $\mathrm{D}$ receives the messages, he will see that message A correctly states "generated by A", but message B states "generated by B" instead of the correct "generated by A". Presentment of the messages to A will similarly warn A of the irregularity. According to Henriksen,

58 Henriksen (n 12) 124-127.

59 What is actually sent is the digital signature of A, ie message A encrypted with A's secret key. A can eg be a "drawer" creating a payment order. See Toh See Kiat (n 28) 170.

60 The acknowledgement of receipt should happen virtually instantaneously because B must not have time to transmit a second copy of the message before the acknowledgement destroys the message on his computer. See Toh See Kiat (n 28) $203 \mathrm{n}$ 64. Alternatively, it is submitted that B's computer should prevent sending the same message before a specified period of time lapses. The problem is not addressed by Henriksen.

61 Before $\mathrm{C}$ could have access to any of the signatures listed here, he had to decrypt all the information he received with his secret key as B encrypted all the information he sent to C by using C's public key. 
"[o]n the face of it" the system is compatible with concepts such as "good faith" and "holder in due course". Printouts of messages or information have no similar legal effect in the system as that of the originals. ${ }^{62}$

It is submitted that the greatest weakness in the system is the fact that each party controls his own computer and may manipulate the computer program. This is admitted by Henriksen, ${ }^{63}$ but he submitted that near-perfect forgery of paper documents can also occur, although only a small number of documents are in fact falsified. It is submitted that one possible solution can be for the parties to log onto a computer system maintained by a trusted independent third party. In such a case, the parties do not have access to the programs running on the system. ${ }^{64}$ Apart from this flaw, the greatest advantage of the system is probably, and ironically, the high level of security. Indeed, only the specific transferor can create the message using his secret key and only the transferee can read the message using his secret key. The messages can be relied on with confidence except if a party reprograms his computer.

Toh See Kiat ${ }^{65}$ identified a further problem. When the final holder transfers the message to the "drawee", the message on that holder's computer is destroyed. If the holder is not paid, how does he prove the fact that the instrument is "dishonoured"? Toh See Kiat submitted that "a presentment for payment in such a system should best be made through a third party, such as a clearing house, which would keep records of the message and corresponding payment credit, if any". Toh See Kiat ${ }^{66}$ also criticised the system for being closed because a central body would have to supply the computer programs and issue the public keys. This is somewhat harsh: no electronic system prior to blockchain would ever be completely open, especially if public-key cryptography is used. It is nevertheless admitted that, without the necessary computer programs, a party would be unable to participate. Toh See Kiat then strangely (as he is usually very positive about the recognition of electronic routines) went on to criticise the system because "a relay of electrons or photons will never be viewed by judges and lawyers as equivalent to the far

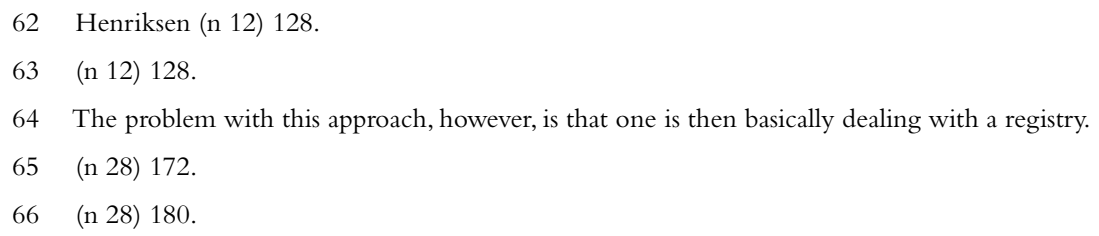


more permanent structure of ink and celluloid molecules that constitutes paper". Of course, there must be a legal framework in which to implement and recognise the system but, thereafter, a delivery is achieved by transferring the message and the whole point of the system is to ensure that there is only one original. ${ }^{67}$ Toh See Kiat ${ }^{68}$ concluded:

"It is difficult to expect conservative, cautious lawyers to adopt concepts associated with paper in a totally alien environment. Old dogs definitely do not learn new tricks, especially the mental gymnastics required for such technical devices. Far better to start with a clean slate, or at least a slate with very few leftovers from the old".

There is no doubt that a functional approach will often be better, but this system developed by Henriksen deserves considerable recognition, even though it will probably never be used extensively in practice. Many other so-called functional approaches relating to the bill of lading are merely electronic variations on registries. Henriksen's system created an electronic negotiable instrument that, to a large extent, lives an independent life similar to its paper sibling. That said, a registry would probably have been a more effective way of designing an alternative to the bill of lading at the time.

\section{Reed's Standalone Dematerialised Instrument}

Reed described what he called a standalone dematerialised instrument. Such a dematerialised instrument must exhibit the same characteristics as a paper instrument: "1. Uniqueness. 2. It evidences the obligation represented by the instrument, e.g., the debt in the case of a bond. 3. It evidences the chain of transfers to the current holder". ${ }^{69}$ Reed wrote that the first and third requirements are linked because, as "it is possible to make an infinite number of copies of an electronic record, each indistinguishable from the original, it is only the chain of transfers which is capable of distinguishing the original from a copy". This is not

67 Toh See Kiat (n 28) 214 n 126 asked: "Where is the document 'issued'? How would you 'deliver' it? Can the message received at the destination be an 'original' since in reality it is a totally different set of electrons from those that began the journey?" Toh See Kiat 180 also questioned whether a bill of lading can be regarded as "clean" in the system. The answer is simply that one looks at the wording of the message, just as one looks at the wording of the traditional bill of lading to determine whether it is clean.

68 (n 28) 180.

69 Reed Electronic Finance Law (1991) 118. 
correct. Without any further special methods as described by Henriksen, once the same message is sent to two different transferees, both chains will look as if they contain a valid chain of transfers. Public-key cryptography is used to ensure the second and third characteristics.

The system will work in the following way. ${ }^{70} \mathrm{~A}$ wants to send a message $\mathrm{e}^{71}$ to B. A encrypts the message with his private key and transmits the encrypted message to $\mathrm{B}$. If $\mathrm{B}$ wants to transfer the message to $\mathrm{C}$, he adds an indorsement to the encrypted message that he received, encrypts the result with his private key and transmits it to C. C decrypts what he received with B's public key, thus showing him the indorsement, and then uses A's public key to show the text of the original message. Up to here, the system is basically the same as that of Henriksen without the three special characteristics. Reed, however, deals with the possibility of $\mathrm{C}$ transmitting the same message to more than one party (that is the issue of uniqueness) in a different way. Reed submitted that A "will presumably be liable to repay only the first recipient of the message, subsequent recipients being limited to an action against [C] for breach of contract or deceit". This, however, showed that one is not dealing here with a standalone instrument yet. Reed therefore proposed that a third party needs to authenticate the transfer and the appropriate third party is simply A. ${ }^{72}$ If A authenticates more than one transfer from one specific party, he will be liable to more than one party for payment. So, if $\mathrm{C}$ in this example transfers the message to $\mathrm{D}, \mathrm{C}$ will request authentication from $\mathrm{A}$ and $\mathrm{A}$ will send authentication of C's ownership directly to D. Reed wrote:

\footnotetext{
"This procedure obviously requires $[\mathrm{A}]$ to maintain detailed records, if only for his own protection. Although it might be argued that $[\mathrm{A}]$ is for all practical purposes maintaining a register of ownership, this is not in fact so. [A's] records are for his own use only, i.e., so as to avoid authenticating multiple transfers of the same bond; the evidence that the bond is unique and has been validly transferred is contained in the dematerialised instrument itself, and can be checked by successfully decrypting the various messages contained in it".
}

\footnotetext{
$70 \quad$ Reed (n 69) 118-119.

71 The example used by Reed (n 69) 118 is that A issues a bond to B.

72 Reed (n 69) 120. See also the figure on $\mathrm{p} 121$.
} 


\title{
Reed $^{73}$ concluded:
}

\begin{abstract}
"The advantages of a stand-alone instrument are that there is no need to invest in the substantial infrastructure of a registry and dedicated telecommunications network. ... If stand-alone instruments are created, they are likely to be used for low-volume, highvalue applications where the trading partners are unlikely to be members of a common electronic trading community".
\end{abstract}

It is indeed unlikely that such a system will ever be used in practice. It is further submitted that, whatever Reed might say, the system is perilously close to being a registry.

\section{FOURTH INDUSTRIAL REVOLUTION}

\section{Blockchain and bills of lading}

An Internet search will turn up numerous blockchain bill-of-lading initiatives ${ }^{74}$ but, for an outsider, there is little information to be found as detailed as the description of the systems proposed by pioneers such as Grönfors, Reinskou, Henriksen and Reed. It is thus not possible to comment in the same manner as has been done above, but at the same time, that is probably not needed. The legal framework that will be examined below is much more technology-neutral than earlier suggested solutions and likely to be capable of adapting to both blockchain and whatever the future may hold.

Blockchain technology made it possible for an electronic bill of lading to be circulated as a token on a blockchain ledger. ${ }^{75}$ Unlike a registry with membership,

73 Reed (n 69) 121.

74 See Bury (n 10) 236 and Chetrit, Danor, Shavit, Yona and Greenbaum "Not just for illicit trade in contraband anymore: using blockchain to solve a millennial-long problem with bills of lading" 2018 Virginia Journal of Law $\mathcal{E}$ Technology 56, 82-83, 92 et seq in respect of Wave: "Wave is a blockchain-based software platform that connects all members of the international trade supply chain to a decentralised network and enables them to directly exchange documents, including bills of lading" (93). The website (wavebl.com (12-05-2019)) does not contain information that would enable further analysis. See Dentons "Blockchain in the energy sector: evolving business models and the law” 2018 International Energy Law Review 233 247-248 and cargox.io (12-05-2019) regarding CargoX; again little information is publicly available. The problems of the traditional bill of lading have often been discussed: see $e g \mathrm{Du}$ Toit (n 6) ch 8.

75 See Takahashi "Blockchain technology and electronic bills of lading” 2016 Journal of International Maritime Law 202. 
the ledger may be an open, decentralised platform. ${ }^{76}$ Such blockchain bills of lading will be unique. ${ }^{77} \mathrm{Ong}^{78}$ explains:

"A blockchain bill of lading system collects all announced transfers of a number of bills of lading into a block at regular intervals through its ledger, which displays the addresses at which the tokens are kept. The ledger operates as a timestamp server ... Blockchain bills of lading can, using timestamping and cryptographic techniques, single out the earliest transfer of a blockchain bill of lading as the authorised transfer and void later unauthorised transfers in the process, enabling blockchain bills of lading to be unique".

The question is whether South African law is able to regulate such blockchain bills of lading effectively.

\section{Recognition of electronic bills of lading}

\section{Electronic Communications and Transactions Act 25 of 2002 ("ECT Act")}

As a point of departure, the ECT Act provides that "[i]nformation is not without legal force and effect merely on the grounds that it is wholly or partly in the form of a data message". ${ }^{79}$ The definitions of "data" and "data message" are wide enough to include the information contained in a bill of lading. ${ }^{80}$ This conclusion is reinforced by the need specifically to exclude bills of exchange from the operation of the Act. ${ }^{81}$ Of further importance is the recognition of the requirements of writing and signature in an electronic domain ${ }^{82}$ and, particularly with reference to a negotiable bill of lading, that of originality. ${ }^{83}$ It is submitted that the section on originality is sufficiently wide - "the integrity of the [data

\footnotetext{
76 Takahashi (n 75) 202, 205-206.

77 Takahashi (n 75) 204-205.

78 (n 9) 11-12.

79 s 11(1).

80 See $\operatorname{eg~s} 1$, where the term "data message" is defined as "data generated, sent, received or stored by electronic means".

$81 \mathrm{~s} 4(3)-(4)$, sch 1 item 3 and sch 2 item 4.

82 s 12-13.

83 s 14.
} 
message] must be assessed ... having regard to all other relevant circumstances" - to recognise only electronic bills of lading that can be regarded as original and unique to the same extent as paper counterparts. ${ }^{85}$ Although the ECT Act seeks to promote technology neutrality, only technology capable of rendering an original and unique bill of lading should underlie the recognition of an electronic bill of lading. Currently, it is submitted, the only technology capable of doing that is blockchain technology.

The Act also states: ${ }^{86}$

"An expression in a law, whether used as a noun or verb, including the terms 'document' ... 'submit','lodge', 'deliver', 'issue' ... or words or expressions of similar effect, must be interpreted so as to include or permit such form, format or action in relation to a data message unless otherwise provided for in this Act".

It is submitted that these terms already provide for an electronic bill of lading being issued, delivered and presented, and one can add to this the "transfer" or "negotiation" 87 of a bill of lading, with "indorsement" if necessary, even stretching to the "holder" of the bill of lading (the list in the section is not exhaustive). It is submitted therefore that the ECT Act provides the necessary legal framework for the recognition of a unique electronic bill of lading. ${ }^{88}$

\section{Sea Transport Documents Act 65 of $2000^{89}$}

According to section 9(1)(a) of the Act, the minister may make regulations "prescribing the circumstances in which and the conditions subject to which a record or document produced by a telecommunication system or an electronic or other information technology system, and effecting transactions such as those effected by any sea transport document, is to be regarded as a sea transport document".

84 s 14(2)(c). See also s 14(2)(a)-(b).

85 s 2(f).

86 s 19(2).

87 Although a bill of lading is not a negotiable instrument, it can be transferred or negotiated. See Du Toit (n 6) 68-72.

88 See also Hare Shipping Law and Admiralty Jurisdiction in South Africa (2009) 725-726. New documents of title can be created by custom (Kum v Wah Tat Bank Ltd 19711 Lloyd's Rep 439 443, 444). Even in the absence of a legislative framework such as the ECT Act, it is suggested that a court should recognise a custom as to electronic bills of lading displaying the characteristics of a document of title or develop the common law if necessary.

89 See Du Toit (n 8) 731-737; Hare (n 88) 669-673. 
No regulations have been made to date. Section 3(1) states that

\begin{abstract}
"A sea transport document may be transferred by the holder, either- (a) by delivery

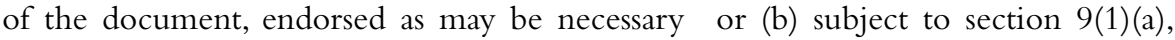
through the use of a telecommunication system or an electronic or other information technology system". ${ }^{90}$
\end{abstract}

It is submitted that, even though there are no regulations in terms of section $9(1)$ (a), section 3(1)(b) allows the negotiation of an electronic bill of lading. It is further submitted, in the absence of regulations and in accordance with the provisions in the ECT Act relating to originality, that only an original and unique electronic bill of lading should be recognised and thus allowed to be negotiated.

\title{
UNCITRAL Model Law on Electronic Transferable Records ("Model Law") ${ }^{91}$
}

Underscored by technology neutrality, and following an approach of functional equivalence, the Model Law does not prescribe the underlying technology that is used - "whether based on registry, token, distributed ledger or other technology" - for the electronic transferable record. ${ }^{92}$ As such, the Model Law provides a framework for the use of blockchain technology, but also for any future technology not currently considered or known that may still be used for the transfer of bills of lading. The Model Law also does not change the substantive law underlying a transferable electronic record..$^{93}$ For example,

90 According to s 3(2)(c) of the Sea Transport Documents Act, the holder is inter alia (see s 3(2)(a)-(b)) the person to whom the document has been transferred in accordance with subsection (1), thus including s 3(1)(b), which mentions an electronic or other information technology system. See Du Toit (n 8) 732-733 for criticism of the section.

91 The Model Law was adopted by the United Nations Commission on International Trade Law (UNCITRAL) on 13 July 2017, with a recommendation that States consider the Model Law favourably when revising or adopting legislation relevant to electronic transferable records. Preceding the Model Law, a number of international instruments could have an influence on electronic bills of lading, including the following: UNCITRAL Model Law on Electronic Commerce (1996 - see Du Toit (n 6) 302-306 for an analysis) art 16 and 17; United Nations Convention on Contracts for the International Carriage of Goods Wholly or Partly by Sea ("Rotterdam Rules") art 1 par 18 and 19 and ch 3; CMI Rules for Electronic Bills of Lading (1990 - see Du Toit (n 6) 281-298 for an analysis). As these instruments precede blockchain bills of lading, further discussion falls beyond the scope of this chapter. For the implementation of the Model Law in Bahrain, see Herd (n 2) 316-317. Generally see Šafranko "The notion of electronic transferable records" 2016 InterEULawEast:J Int'l \& Eur L, Econ \& Market Integrations 1; Ong (n 9) 12 et seq.

92 Explanatory Note to the UNCITRAL Model Law on Electronic Transferable Records ("Explanatory Note") par 18. See the description of an "electronic transferable record" in terms of art 10 quoted below. The term "electronic record" is defined in art 2.

93 Model Law art 2; Explanatory Note par 22. 
"The Model Law focuses on the transferability of the record and not on its negotiability on the understanding that negotiability relates to the underlying rights of the holder of the instrument, which fall under substantive law". ${ }^{94}$

Article 7(1) provides the usual principle of non-discrimination that is found in international instruments and statutes dealing with electronic commerce: "An electronic transferable record shall not be denied legal effect, validity or enforceability on the sole ground that it is in electronic form". A comprehensive analysis of the Model Law is not undertaken in this contribution, but sections that may be significant for blockchain bills of lading are examined below, with the aim to express a view on their suitability in South African law.

Chapter II of the Model Law deals with functional equivalence, starting with the usual sections on writing and signature in articles 8 and $9 .{ }^{95}$ Article 10 considers transferable documents and instruments:

"1. Where the law requires a transferable document or instrument, that requirement is met by an electronic record if:

(a) The electronic record contains the information that would be required to be contained in a transferable document or instrument; and

(b) A reliable method is used:

(i) To identify that electronic record as the electronic transferable record;

(ii) To render that electronic record capable of being subject to control from its creation until it ceases to have any effect or validity; and

(iii) To retain the integrity of that electronic record.

2. The criterion for assessing integrity shall be whether information contained in the electronic transferable record, including any authorized change that arises from its creation until it ceases to have any effect or validity, has remained complete and unaltered apart from any change which arises in the normal course of communication, storage and display".

94 Explanatory Note par 20.

95 See the discussion in Explanatory Note par 68-79. In the case of distributed ledgers, pseudonyms rather than real names may be used to identify the signatory: "That identification, and the possibility of linking pseudonym and real name, including based on factual elements to be found outside distributed ledger systems, could satisfy the requirement to identify the signatory" (par 78; see also par 117 in respect of article 11). 
According to the Explanatory Note, ${ }^{96}$ article 10 reflects the outcome of discussions regarding the "uniqueness" of a transferable instrument - a "peculiar challenge" in an electronic environment, as has already been intimated in the introduction to this chapter. Multiple claims for the performance of the same obligation are avoided by notions of "singularity" (the basis of article 10) and "control" 97 as set out in article 11. The Model Law steered away from using the term "original" 98 as a "static notion" in favour of these terms due to the dynamic nature of electronic transferable records - they circulate and may only be in a final form upon presentation. ${ }^{99}$ Article 11 provides:

"1. Where the law requires or permits the possession of a transferable document or instrument, that requirement is met with respect to an electronic transferable record if a reliable method is used:

-2 . Where the law requires or permits transfer of possession of a transferable document or instrument, that requirement is met with respect to an electronic transferable record through the transfer of control over the electronic transferable record".

It was suggested above that the control of an electronic bill of lading may be covered by the provisions of the ECT Act and the Sea Transport Documents Act, but an express provision such as article 11 is to be preferred. Referring to "exclusive" control may be superfluous in terms of South African law, but such a reference can be included for clarity in an electronic environment. ${ }^{100}$ Of course, in accordance with the underlying substantive law, control or possession ${ }^{101}$ does not equate to lawful control. Flowing from article 11(2), article 15 deals more specifically with the indorsement of a transferable electronic record:

"Where the law requires or permits the endorsement in any form of a transferable document or instrument, that requirement is met with respect to an electronic

\footnotetext{
96 par 81.

97 Explanatory Note par 81-85. The notions of "singularity" and "control" are different and should be distinguished: see par 112.

98 Multiple "originals" (even on different media) may still be issued in terms of the Model Law: see Explanatory Note par 191-195 and Du Toit (n 6) 110-111.

99 Explanatory Note par 189-190.

100 Explanatory Note par 111.

101 The terms "possession" and "control" are used interchangeably and in accordance with the use in an international instrument such as the Model Law. See Du Toit (n 6) 103 n 146.
} 
transferable record if the information required for the endorsement is included in the electronic transferable record and that information is compliant with the requirements set forth in articles 8 [writing] and 9 [signature]".

As before, the aim of the section is functional equivalence without changing the substantive law. ${ }^{102}$ The Model Law also provides for the amendment of an electronic transferable record, ${ }^{103}$ thus, it is submitted, catering for an instance such as the substitution of the name of the consignee. Lastly, the Model Law deals with the replacement of a paper instrument ${ }^{104}$ with an electronic transferable record (article 17) and the replacement of an electronic transferable record with a paper instrument (article 18). ${ }^{105}$ Such changes of medium may be necessary where, for example, there are different levels of acceptance of electronic bills of lading among parties and across borders. ${ }^{106}$ These are matters not covered by the underlying substantive law (for instance the fact that the paper instrument shall be made inoperative and will cease to have any effect or validity in terms of article 17(3)), so the inclusion is to be welcomed and brings legal certainty.

Although the discussion here focused on only a few of the articles of the Model law, it is submitted that the Model Law can - and should - be made part of South African law with very few amendments. It is further submitted that the minister may make the Model Law part of regulations envisaged in terms of section 9(1)(a) of the Sea Transport Documents Act.

\section{SYMBOLIC DELIVERY ${ }^{107}$}

The requirements for symbolic delivery are: ${ }^{108}$

"(a) the parties must have the intention to resort to this form of delivery; (b) the keys must be delivered with the intention that the contents of the warehouse and so forth are thereby transferred; and (c) the keys must supply the transferee with exclusive

102 See Explanatory Note par 150-152.

103 art 16. Cf Du Toit (n 6) 123-124 and Numill Marketing CC v Sitra Wood Products Pte Ltd 19943 SA 460 (C).

104 See the definition of a "transferable document or instrument" in art 2 of the Model Law.

105 See Explanatory Note par 161-179.

106 See Explanatory Note par 161 and 176; $f$ Du Toit (n 6) 317-319.

107 The terms clavium traditio and traditio symbolica are also used.

108 Van der Merwe “Things” 201427 LAWSA par 221; Sakereg (1989) 316; Du Toit (n 6) 108. Delivery is only one of the requirements for the derivative acquisition of ownership. See also Van der Merwe supra (1989) 301-305. 
control over the contents of the warehouse and so forth".

It has long been held that transferring (or negotiating) the bill of lading can amount to symbolic delivery of the goods: ${ }^{109}$

"The key [the handing over of which effects delivery of the goods in a warehouse] is the symbol of the property in the goods placed in the warehouse, in the same way as the bill of lading is the symbol of the property in the goods shipped on board".

Although it may be more correct to refer to a form of delivery "closely analogous" 110 to symbolic delivery, or even "an effective form of constructive delivery sui generis", ${ }^{111}$ such distinction is not made by the courts. It is not, however, about the symbol as such; the symbol must enable the transferee to exercise control over the goods:

"No doubt a mere symbol is not sufficient to effect delivery; the goods must be subjected to the power of the person to whom delivery is to be made... The key is in one sense symbolical, but it is more than that, for it is the means by which the pledgee is enabled to have access to and retain control of the goods". ${ }^{112}$

\section{As stated in Knight $v$ Lensvelt, ${ }^{113}$}

"the change of physical control can be effected by placing the purchaser in possession of the means of dealing effectively with the property ... or in other words, placing the property in the power of the purchaser".

109 London and South African Bank v Donald Currie \& Co (1875) 5 Buch 29 34. For a full analysis of the preceding and subsequent case in South Africa and England, see Du Toit (n 6) 91 et seq.

110 Van der Merwe (n 108 (2014)) par 221.

111 Carey Miller "Transfer of ownership" in Zimmermann andVisser (eds) Southern Cross - Civil Law and Common Law in South Africa (1996) 727741 - thus "not so much symbolic delivery as the only appropriate means of dealing with the goods in transit".

112 Heydenrich v Saber (1900) 17 SC 73, 76-77; S v Magxwalisa 19842 SA 314 (N) 321A. Carey Miller ("Transfer of ownership" in Feenstra and Zimmermann (eds) Das römish-holländische Recht-Fortschritte des Zivilrechts im 17. und 18. Jahrhundert (1992) 521 529; (n 111) 740) points out that the Roman and Roman-Dutch authorities are inconclusive on the question.

1131923 CPD 444447 (own emphasis). 
The question is whether these "means" can also include some form of electronic bill of lading. Most of the Roman ${ }^{114}$ and Roman-Dutch ${ }^{115}$ texts refer to no more than the "key" or "keys" of, inter alia, a warehouse.Voet ${ }^{116}$ wrote that

\begin{abstract}
"[i]t is symbolical or figurative when it takes place by a symbol, that is to say an external token given in place of delivery". The use of the word "token" in Gane's translation of Voet is an interesting quirk because the term is today also used within the context of blockchain - but of course it is not suggested that anything turns on this. According to Huber, ${ }^{117}$ " $[s] y m b o l i c a l$ delivery is when in place of delivering the property itself you hand over something that has the significance of such property".
\end{abstract}

It is submitted that a blockchain bill of lading can be the "means", "token" or "something that has the significance of such property" for purposes of effecting symbolic delivery - quite apart from any development regarding symbolic delivery or an analogous form of delivery that courts must surely sanction in the era of the Fourth Industrial Revolution. Depending on its implementation, it is further submitted that the publicity requirement ${ }^{118}$ may be fulfilled better by the information in the distributed ledger, than would have been the case when using a paper bill of lading to effect delivery.

\title{
CONCLUSION
}

The idea to embody personal rights in a piece of paper was revolutionary. Some time ago, Malan ${ }^{119}$ wrote:

\begin{abstract}
"The ingenuity of the bill of exchange lies in its tangibility....The achievement of the medieval merchants was to incorporate their intangible rights of action against their trading partners in the corporeal paper and to make transfer of these rights dependent
\end{abstract}

114 I2 $145 ; D 18174 ; D 41196 ; D 412121$.

115 De Groot Inleidinge 25 12;Van Leeuwen Simon van Leeuwen's Commentaries on Roman-Dutch Law (trans Kotzé 1886) 27 2;Van der Keessel Praelectiones Iuris Hodierni ad Hugonis Grotii Introductionem ad Iurisprudentiam Hollandicam (Afrikaans trans Gonin assisted by Pont) in addition deals with the delivery of documents showing ownership of a movable.

116 Commentarius ad Pandectas 41134 (trans Gane 1957); a different translation (Krause), referring to an "outward token" is quoted in Meintjes $v$ Wilson 1927 OPD 183 187-188; and, in Laljee v Omdadutt (1883) 4 NLR 117 118119 , a translation referring to an "external symbol or sign" is mentioned.

117 Heedensdaegse Rechtsgeleertheyt 2914 (trans Gane 1939).

118 See Van der Merwe (n 108 (1989)) 300-301.

119 Malan "Legal implications of electronic storage" 1990 Stell LR 153154. 
on the fate of the instrument. They flouted existing and traditional legal norms and subjected them to the requirements of the marketplace. They made law and lawyers have never ceased to wonder at their audacity".

It may be rather early to express an opinion on the matter, but blockchain technology may well have a similar impact on the law as the notion of embodying rights in paper had a long time ago. It is submitted that, in the case of blockchain bills of lading, a sensible interpretation of current legislation, together with the flexibility of the common law, would be able to provide the necessary legal framework for such bills of lading. It is nevertheless suggested that the Model Law will bring further legal certainty and harmonisation with other jurisdictions, for the benefit of global maritime trade. 